\title{
Physiological effects of touching hinoki cypress (Chamaecyparis obtusa)
}

\author{
Harumi Ikei ${ }^{1,2}\left(\right.$ Chorong Song $^{2}\left[\right.$ [ $\cdot$ Yoshifumi Miyazaki² $^{2}$
}

Received: 24 September 2017 / Accepted: 11 December 2017 / Published online: 19 January 2018

(C) The Author(s) 2018. This article is an open access publication

\begin{abstract}
This study aimed to clarify the physiological effects of touching hinoki cypress (hereinafter called "hinoki") (Chamaecyparis obtusa) wood with the palm of the right hand on brain activity and autonomic nervous activity. Twenty-two female university students (mean age $21.1 \pm 0.2$ years) participated in the study. As an indicator of brain activity, oxyhemoglobin (oxy-Hb) concentrations were measured in the left/right prefrontal cortex using near-infrared time-resolved spectroscopy. Heart rate variability (HRV) was used as an indicator of autonomic nervous activity. The high-frequency (HF) component of HRV, which reflected parasympathetic nervous activity, and the low-frequency (LF)/HF ratio, which reflected sympathetic nervous activity, were measured. Plate $(300 \times 300 \mathrm{~mm})$ of uncoated hinoki was used as tactile stimulation. Marble was used as a control material. After sitting at rest with their eyes closed, the participants touched the materials for $90 \mathrm{~s}$ with their eyes still closed. The results showed that tactile stimulation with hinoki significantly decreased oxy-Hb concentration in the left prefrontal cortex and increased $\ln (\mathrm{HF})$ reflected parasympathetic nervous activity compared with marble. In conclusion, our study showed that touching hinoki wood with the palm calms prefrontal cortex activity and increases parasympathetic nervous activity, thereby inducing physiological relaxation.
\end{abstract}

Keywords Japanese cypress · Tactile · Autonomic nervous activity $\cdot$ Prefrontal cortex activity $\cdot$ Physiological relaxation

\section{Introduction}

The stress that modern society brings on humans, especially "technostress [1]," is known to cause an increase in stress conditions [2]. In 2008, it was reported that more than 3.3 billion people - half of the globe's population - lived in an urban environment [3]. Lederbogen et al. [4] showed that social stressors increased the amygdala activity of the brain more in urban residents than in rural residents. Therefore,

Harumi Ikei and Chorong Song are co-first authors who contributed equally to this work.

Part of this study was presented at the 67th Annual Meeting of the Japan Wood Research Society, Fukuoka, March 2017.

Yoshifumi Miyazaki

ymiyazaki@faculty.chiba-u.jp

1 Forestry and Forest Products Research Institute, 1 Matsunosato, Tsukuba, Ibaraki 305-8687, Japan

2 Center for Environment, Health and Field Sciences, Chiba University, 6-2-1 Kashiwa-no-ha, Kashiwa, Chiba 277-0882, Japan urban residents react excessively to stress. Because of the stressful conditions of modern society, the effects of exposure to natural stimuli on relaxation are receiving increasing attention [5].

Wood is a familiar, natural material that is used in houses and furniture, and it is empirically known to have a relaxing effect on humans [6]. A review outlining the current state of research regarding the physiological effects of wood-derived stimulation on humans [6] reported that data on the physiological effects of olfactory stimulation have continued to accumulate, following the development of physiological measurement technology in recent years. The oldest report, published in 1992, focused on the physiological effect of olfactory stimulation with Taiwan cypress oil [7], and several other reports have been published since. In recent years, the physiological relaxation effects of stimulation by olfactory stimuli such as air-dried hinoki cypress (hereinafter called "hinoki") (Chamaecyparis obtusa) wood chips [8], $\alpha$-pinene [9], and ${ }_{\mathrm{D}}$-limonene [10], which are components derived from wood, have been reported. Several studies on visual stimulation have also been conducted using 
rooms with different designs and proportions of wood [11-13] and large wall panels [14]. In contrast, there have been extremely few reports on tactile stimuli.

Regarding the physiological effects of tactile stimulation by wood, Morikawa et al. [15] reported differential effects on blood pressure from touching plates of hinoki wood vs. artificial material. Sakuragawa et al. [16] examined differences in the effects of tactile stimulation on human physiology that resulted from materials at different temperatures (cool, room temperature, and warm). They found that touching an aluminum plate increased blood pressure, but the increase was inhibited when the aluminum was warmed; touching an acrylic plastic plate increased blood pressure, and a greater rate of increase was observed when the acrylic was chilled; and blood pressure did not change in response to touching objects made of hinoki, Japanese cedar, or oak, and did not increase even when the oak was chilled. These reports are pioneering studies on the physiological effects of tactile stimulation with wood on humans. However, they have limitations in that they only examined blood pressure, which is an index of autonomic nervous activity, as a measure of the physiological response to stimuli.

In our previous research, we examined the physiological effects on brain activity and autonomic nervous activity of touching wood with the palm of the hand $[17,18]$. As an indicator of brain activity, oxyhemoglobin (oxy-Hb) concentration was measured in the left/right prefrontal cortex using near-infrared time-resolved spectroscopy (TRS). Heart rate variability (HRV) was used as an indicator of autonomic nervous activity. White oak, a broad-leaved tree generally used as an interior material, was used as a sample. The results indicated that touching uncoated white oak wood with the palm calmed prefrontal cortex activity $[17,18]$, increased parasympathetic nervous activity [17, 18], and decreased heart rate [18] more than did various building materials [17] and coated wood materials [18], thereby inducing physiological relaxation. However, there have been no reports of the effects on physiological responses of tactile stimulation (with the palm of the hand) by wood of coniferous trees.

This study, therefore, aimed to clarify the physiological effects of touching hinoki, which is one of the typical coniferous trees, with the palm of the hand in comparison with touching marble, a natural, nonwood building material. As physiological responses, brain activity (oxy- $\mathrm{Hb}$ concentration in left/right prefrontal cortex assessed with TRS) and autonomic nervous activity (sympathetic/parasympathetic nervous activity, assessed by HRV, and heart rate) were measured.

\section{Materials and methods}

\section{Participants}

The study participants were 22 female university students (mean age $21.1 \pm 0.2$ years). We excluded smokers, those currently in treatment for disease, and those who had menstrual periods during the study period. The participants were informed about the aim and procedures of the experiment before providing written informed consent to participate. Informed consent was obtained from all individual participants. The study was performed in accordance with the regulations of the Ethics Committee of the Center for Environment, Health and Field Sciences, Chiba University, Japan (Project Identification Code Number 5).

\section{Study protocol}

Physiological measurements were performed in a chamber with an artificial climate maintained at $25{ }^{\circ} \mathrm{C}, 50 \%$ relative humidity, and $230 \mathrm{~lx}$ illumination. In the waiting room, the participants received a description of the experiment and then moved into the chamber. After sensors for physiological measurement were fitted to the participant's forehead and chest, they received a description of the measurement procedure while in a seated position. Next, they practiced touching the stimulus with their palm using a dummy sample (sheet laminated flooring). Sheet laminate flooring was selected as a dummy sample since it is an artificial material used as an interior material in general. The experimental procedure was as follows. Participants rested with their eyes closed for $60 \mathrm{~s}$ (Fig. 1, left). Upon receiving instructions from the experimenter, they moved their right forearm using their elbow as a fulcrum and placed the palm on the stimulus (hereafter referred to as the "material") with their eyes closed for $90 \mathrm{~s} \mathrm{(Fig.} \mathrm{1,} \mathrm{right).} \mathrm{After} \mathrm{touching} \mathrm{the} \mathrm{material}$ for $90 \mathrm{~s}$, they returned their hand to the previous position with their eyes closed upon the experimenter's instruction (Fig. 1, left). The experimenter then replaced the current material with the subsequent material, hid it with a cloth, and instructed participants to open their eyes. Subsequently, participants completed the subjective evaluation test. Figure 2 shows the experimental schedule. The materials were presented in a counterbalanced order to eliminate any effects due to the order of tactile stimulation. The physiological responses were measured continuously.

\section{Tactile stimulation}

Hinoki (Chamaecyparis obtusa) wood grown in Shizuoka Prefecture, Japan, was used as the base material. Three 


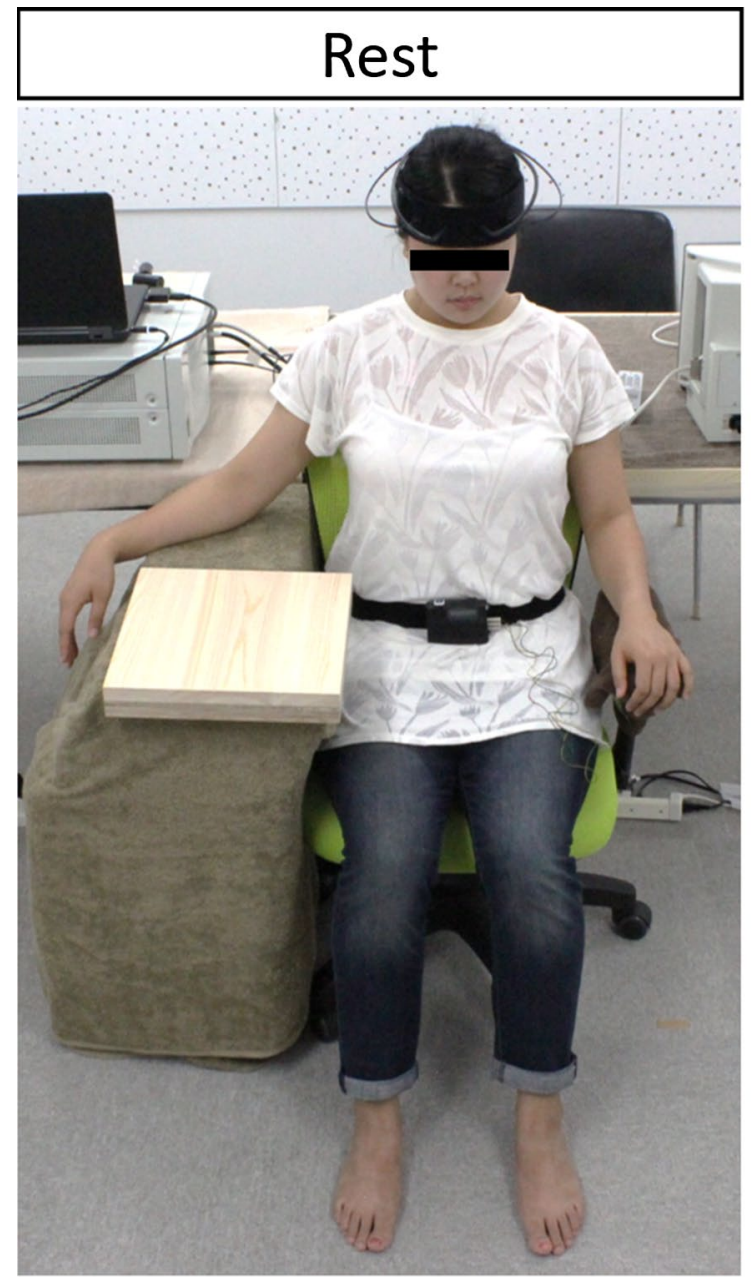

\section{Contact with material}

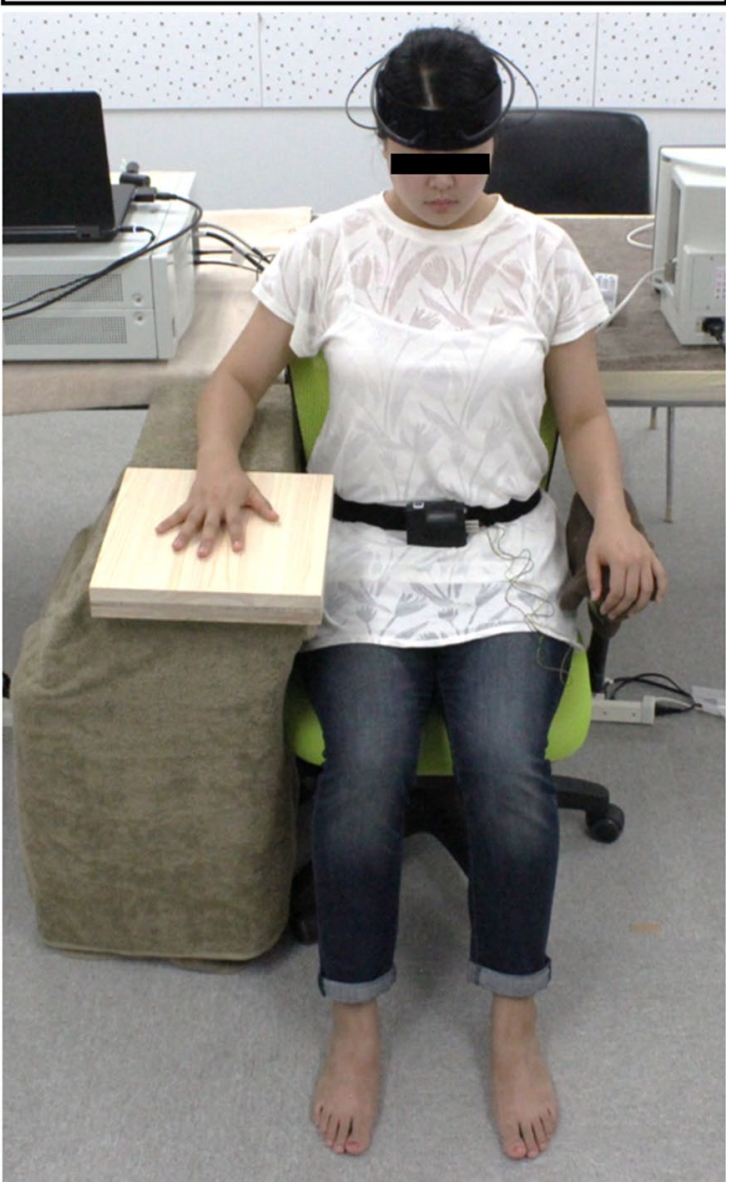

Fig. 1 Experimental setup

Fig. 2 Experimental schedule. $T R S$ near-infrared time-resolved spectroscopy, $H R V$ heart rate variability

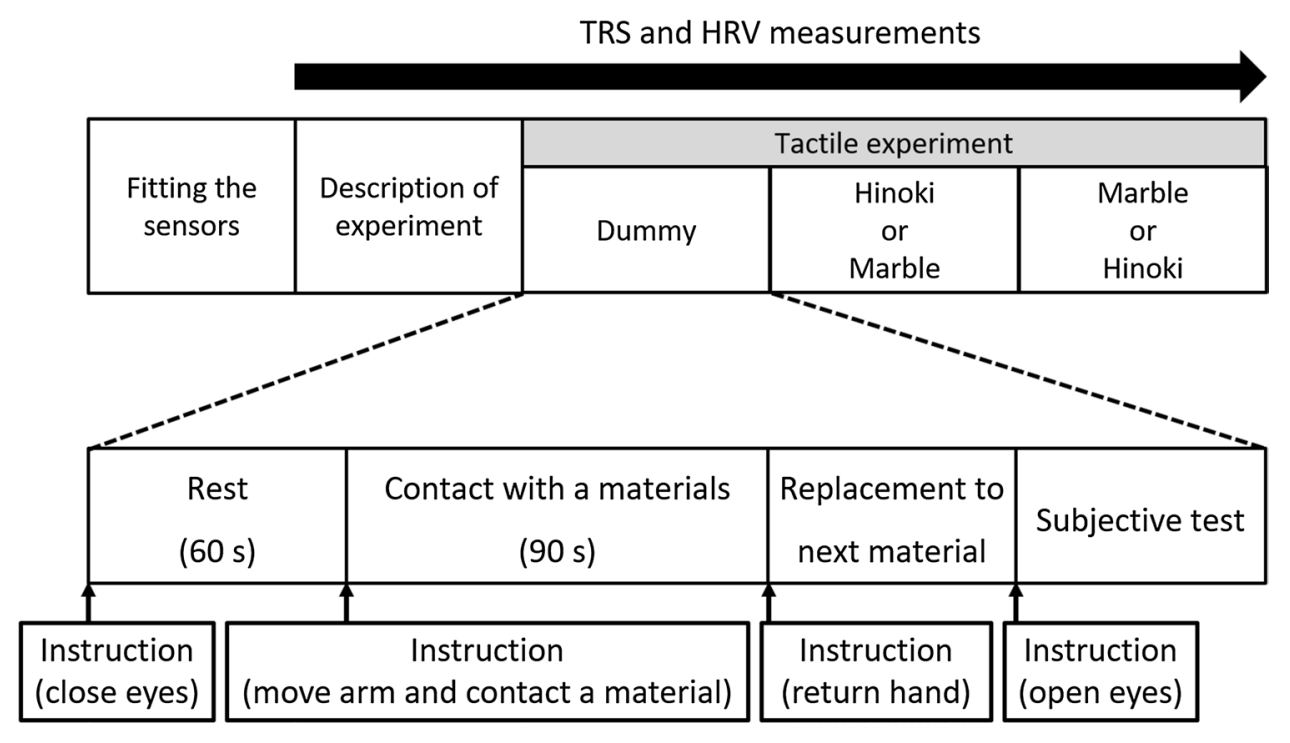


laminae without vertical joints (size of each lamina = length $300 \times$ width $100 \times$ thickness $20 \mathrm{~mm}$ ) were mutually bonded using a water-based polymer isocyanate adhesive along the width of each wood plate. To prevent bending, a second bonding was performed using Japanese cedar (Cryptomeria japonica) plywood (length $300 \times$ width $300 \times$ thickness $25 \mathrm{~mm}$ ); the total thickness of the material was $45 \mathrm{~mm}$. The surface of the hinoki material was finished by brushing it with a stainless steel wire brush (Fig. 3a).

As a control material, marble, which is used as a building material, was selected. The size of the marble material was $300 \times 300 \times 20 \mathrm{~mm}$. It was placed on a piece of cedar plywood of the same size as those that were bonded to the hinoki, and presented to the participant. The surface was processed by buffing (Fig. 3b).

Although the surface roughness of materials varies widely depending on differences in sanding methods, both samples used in this experiment were evaluated in their general original state.

All materials were kept at room temperature. The physical properties of the materials are shown in Table 1.

\section{Physiological measurements}

\section{TRS}

TRS, which is a near-infrared spectroscopy method, was used as an indicator of brain activity. Sensors were mounted on the participant's forehead, and oxy-Hb concentrations in the prefrontal cortex were measured by a TRS-20 system (Hamamatsu Photonics K.K., Shizuoka, Japan) [21-23]. The oxy-Hb concentrations in the left and right prefrontal cortex
Table 1 Details of samples

\begin{tabular}{llllll}
\hline Material & $\begin{array}{l}h \\
(\mathrm{~mm})\end{array}$ & $\begin{array}{l}\lambda \\
(\mathrm{W} /(\mathrm{mK}))^{\mathrm{a}}\end{array}$ & $\begin{array}{l}\rho \\
\left(\mathrm{g} / \mathrm{cm}^{3}\right)^{\mathrm{b}}\end{array}$ & $\begin{array}{l}R a \\
(\mu \mathrm{m})^{\mathrm{c}}\end{array}$ & Condition \\
\hline Hinoki & $\begin{array}{l}20 \\
(+\mathrm{JCP} 25)\end{array}$ & 0.133 & 0.52 & 54.74 & Brushing \\
Marble & $\begin{array}{l}20 \\
(+\mathrm{JCP} 25)\end{array}$ & 0.186 & 1.87 & 0.08 & Buffing \\
\hline
\end{tabular}

$h$ thickness of material, $\lambda$ thermal conductivity, $\rho$ density of material, $R a$ arithmetic average roughness, JCP Japanese cedar plywood

${ }^{a}$ A heat flow meter (HFM 436 Lambda; NETZSCH, Selb, Germany), tuned according to ASTM C518-10 [19] and ISO8310 [20], was used. The direction of heat flow was vertically downward. The temperatures of the high- and low-temperature heat plates were 35 and $15^{\circ} \mathrm{C}$, respectively. The thermal conductivity at an average material temperature of $25^{\circ} \mathrm{C}$ was calculated. The test specimens were used with the cedar plywood attached

${ }^{\mathrm{b}}$ The samples were cured under the same environmental conditions as used in the thermal conductivity measurement; the mass was measured, and the density calculated. The samples with the cedar plywood adhered were used

${ }^{\mathrm{c}}$ A contact surface roughness profilometer (SE3500; Kosaka Laboratory Ltd., Tokyo, Japan) with a diamond needle was used. The evaluation length was $50 \mathrm{~mm}$. The central portion of the samples was measured five times with 50-mm spacing, and the average value was calculated

were measured before the participant touched the materials (premeasurement) and during the $90 \mathrm{~s}$ during which the participant touched the materials (postmeasurement). Because all data were obtained at approximately 1.0-1.2 s, they were transformed by linear interpolation every $1 \mathrm{~s}$. In addition, all data were calculated as the difference between the averages of the 30 -s values before touching.
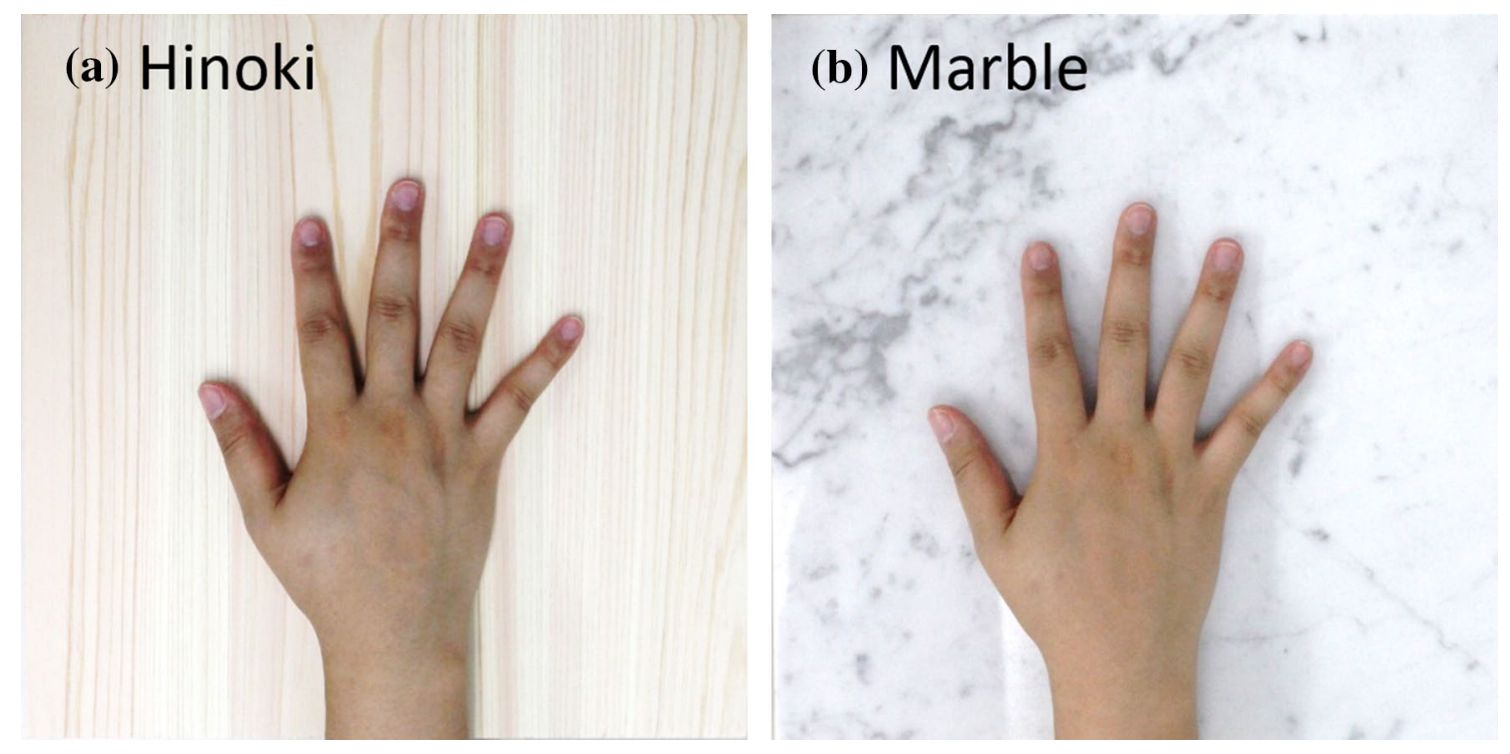

Fig. 3 Materials used in the tactile experiment. a Uncoated hinoki wood; b marble material 


\section{HRV and heart rate}

HRV and heart rate were used as indicators of autonomic nervous activity. HRV was analyzed during the periods between consecutive $\mathrm{R}$ waves ( $\mathrm{R}-\mathrm{R}$ intervals) on electrocardiograms measured with a portable electrocardiograph (Activtracer AC-301A; GMS, Tokyo, Japan) [24, 25]. The power levels of the low-frequency (LF) $(0.04-0.15 \mathrm{~Hz})$ and high-frequency (HF) $(0.15-0.40 \mathrm{~Hz})$ components of HRV were calculated using the maximum-entropy method (MemCalc/Win; GMS, Tokyo, Japan) [26, 27]. HF power reflected parasympathetic nervous activity, and the LF/HF ratio reflected sympathetic nervous activity $[28,29]$. To normalize HRV parameters across participants, natural logarithmic-transformed values were used in the analysis [30]. The values of $\ln (\mathrm{HF}), \ln (\mathrm{LF} / \mathrm{HF})$, and heart rate represented the changes that occurred in each $30 \mathrm{~s}$ and the overall mean during the $90 \mathrm{~s}$ in which participants touched the materials.

\section{Psychological measurement}

The modified semantic differential (SD) method [31] was used to evaluate the psychological effects of touching the two samples. The SD method tests the subjective evaluations of participants through a questionnaire with opposing adjectives, each of which is evaluated on a 13-point scale. Seven pairs of adjectives were assessed: "comfortable-uncomfortable", "relaxed-awakening", "natural-artificial", "warm-cold", "uneven-flat", "dry-moist", and "soft-hard".

\section{Statistical analysis}

Statistical Package for Social Sciences software (v21.0, IBM Corp., Armonk, NY, USA) was used for all statistical analyses. In all cases, $p<0.05$ was taken to indicate statistical significance.
In physiological indices, regarding changes in each $30 \mathrm{~s}$, paired $t$ tests with Holm correction [32] were used to compare physiological responses between hinoki and marble materials; thus, the Holm correction [32] was applied three times. The Holm correction procedure is as follows. First, all $p$ values are sorted by size and then compared with increasing limits. The lowest limit is the overall limit divided by 3 ; the smallest $p$ value is to be compared with $0.05 / 3$ or ca. 0.017 . The second smallest $p$ value is to be compared with $0.05 / 2=0.025$. The third smallest $p$ value is to be compared with $0.05 / 1=0.05$. Null hypotheses can be rejected if the corresponding $p$ values are less than the corresponding limit. However, this only applies until the limit is exceeded for the first time.

Regarding the overall mean in $90 \mathrm{~s}$, paired $t$ tests were used to compare physiological responses before and after touching each material (i.e., pre- vs. postmeasurement) and between hinoki and marble materials. In psychological indices, Wilcoxon signed-rank tests were applied to analyze the differences in psychological indices between hinoki and marble materials.

One-sided tests were used for all comparisons because our hypothesis was that humans would be more relaxed after touching the wood than after touching the other materials.

\section{Results}

\section{Physiological effects}

\section{TRS}

Figure 4a shows the changes in the oxy-Hb concentration in the left prefrontal cortex while the participant was touching hinoki and marble materials. Between 0 and $1 \mathrm{~s}$ (immediately after touching) and between 29 and $30 \mathrm{~s}$, the oxy- $\mathrm{Hb}$

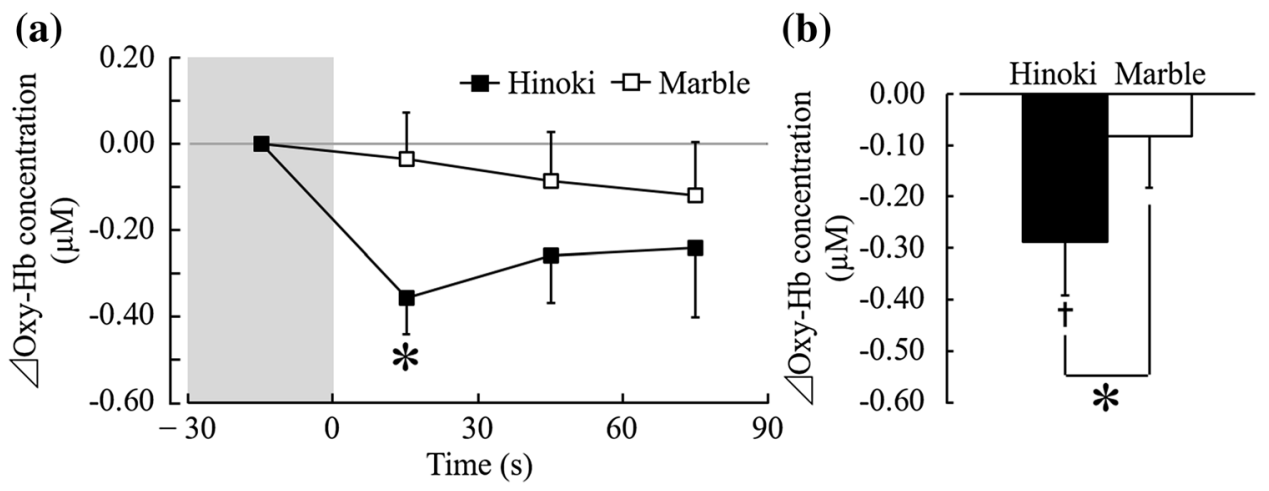

Fig. 4 Thirty-second average and overall mean oxyhemoglobin (oxy$\mathrm{Hb}$ ) concentration in left prefrontal cortex while touching hinoki or marble materials. a Changes in each 30 -s average oxy-Hb concentration over 90 s. b Overall mean oxy-Hb concentration. Data are expressed as means \pm standard error, $n=22,{ }^{\dagger} p<0.05$ (comparing pre- vs. postmeasurement value), $* p<0.05$ (comparing hinoki vs. marble materials) as determined by the paired $t$ test (one-sided); the Holm correction was applied 
concentration was $-0.36 \pm 0.08 \mu \mathrm{M}$ during contact with hinoki and $-0.04 \pm 0.11 \mu \mathrm{M}$ during contact with marble; analysis of the difference indicated that the oxy-Hb concentration was significantly decreased after touching hinoki compared with marble (Fig. 4a, $p<0.05$ ). Figure $4 \mathrm{~b}$ shows a comparison of the average differential (post- to premeasurement) oxy-Hb concentration value in the left prefrontal cortex while the participant was touching hinoki and marble materials. Oxy-Hb concentrations in the left prefrontal cortex was $-0.29 \pm 0.10 \mu \mathrm{M}$ for hinoki and $-0.08 \pm 0.10 \mu \mathrm{M}$ for marble. Touching hinoki significantly decreased oxy$\mathrm{Hb}$ concentration compared with touching marble (Fig. 4b, $p<0.05)$. The oxy-Hb concentration was also significantly decreased after touching hinoki compared with the premeasurement value (Fig. 4b, $p<0.05$ ). Incidentally, the mean baseline for 30-s oxy-Hb concentration before touching did not significantly differ between hinoki and marble materials $(43.67 \pm 1.24 \mu \mathrm{M}$ for hinoki and $43.27 \pm 1.31 \mu \mathrm{M}$ for marble; $p>0.05)$.

However, in comparisons between the pre- and postmeasurement values and between hinoki and marble, there were no significant differences in oxy-Hb concentration in the right prefrontal cortex $(-0.20 \pm 0.11 \mu \mathrm{M}$ for hinoki and $-0.17 \pm 0.09 \mu \mathrm{M}$ for marble; $p>0.05)$.

\section{HRV and heart rate}

Figure 5a shows the changes in $\ln (\mathrm{HF})$ values, which reflect parasympathetic nervous activity, between touching hinoki and marble materials. Between 0 and $1 \mathrm{~s}$ and between 29 and $30 \mathrm{~s}$, the $\ln (\mathrm{HF})$ value was $6.47 \pm 0.201 \mathrm{nms}^{2}$ during contact with hinoki and $6.13 \pm 0.19 \mathrm{lnms}^{2}$ during contact with marble; analysis of the difference indicated that $\ln (\mathrm{HF})$ was significantly increased after touching hinoki compared with marble (Fig. 5a, $p<0.05$ ). Figure 5 b shows a comparison of the average $\ln (\mathrm{HF})$ values while touching hinoki and marble materials. The $\ln (\mathrm{HF})$ values were $6.31 \pm 0.191 \mathrm{nms}^{2}$ for hinoki and $6.08 \pm 0.20 \mathrm{lnms}^{2}$ for marble. Touching hinoki significantly increased $\ln (\mathrm{HF})$ compared with touching marble material (Fig. 5b, $p<0.05$ ). Incidentally, the mean baseline for $30 \mathrm{~s} \ln (\mathrm{HF})$ before touching did not significantly differ between hinoki and marble materials $\left(6.09 \pm 0.23 \mathrm{lnms}{ }^{2}\right.$ for hinoki and $6.07 \pm 0.18 \mathrm{lnms}^{2}$ for marble; $\left.p>0.05\right)$.

However, in comparisons between hinoki and marble, there were no significant differences in the $\ln (\mathrm{LF} / \mathrm{HF})$ ratio, which is an index of sympathetic nervous activity $(0.96 \pm 0.03$ for hinoki and $0.94 \pm 0.03$ for marble; $p>0.05)$, and heart rate $(68.45 \pm 1.59$ beats/min for hinoki and $68.10 \pm 1.64$ beats/min for marble; $p>0.05)$.

\section{Psychological effects}

The results of subjective evaluation by the modified SD method are shown in Fig. 6.

With regard to "comfortable" feeling, the participants reported subjectively feeling "slightly comfortable" after touching hinoki and "indifferent" after touching marble. Therefore, touching hinoki was believed to induce significantly more comfort than touching marble (Fig. 6a, $p<0.01$ ). With regard to "relaxed" feeling, the participants reported subjectively feeling "slightly relaxed" while touching hinoki and "indifferent to slight awakening" while touching marble. Thus, hinoki induced significantly more relaxation than marble (Fig. 6b, $p<0.01$ ). With regard to "natural" feeling, hinoki was perceived as "slightly to moderately natural", which was significantly more natural than marble, which was perceived as "slightly to moderately artificial" (Fig. 6c, $p<0.01)$. With regard to "warm-cold" feeling, the participants reported feeling "indifferent to slightly warm" after contact with hinoki and "moderately to very cold" after touching marble. Therefore, it was reported that touching hinoki was perceived as significantly warmer than touching marble (Fig. 6d, $p<0.01$ ). With regard to "uneven-flat" feeling, hinoki, which was perceived as "slightly to moderately
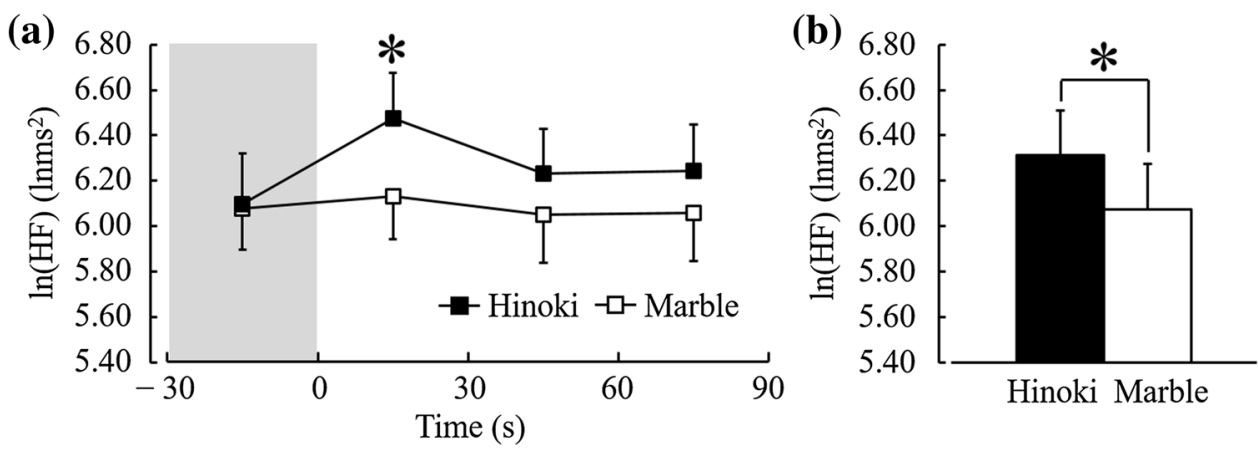

Fig. 5 Thirty-second averages and overall mean of the natural logarithm of the high-frequency (HF) component of heart rate variability (HRV) while touching hinoki or marble materials. a Changes in each 30 -s average HF value over $90 \mathrm{~s}$. b Overall mean HF values. Data are expressed as means \pm standard error, $n=22$, $* p<0.05$ (comparing hinoki vs. marble materials) as determined by the paired $t$ test (one sided); the Holm correction was applied 
(a) "Comfortable" feeling

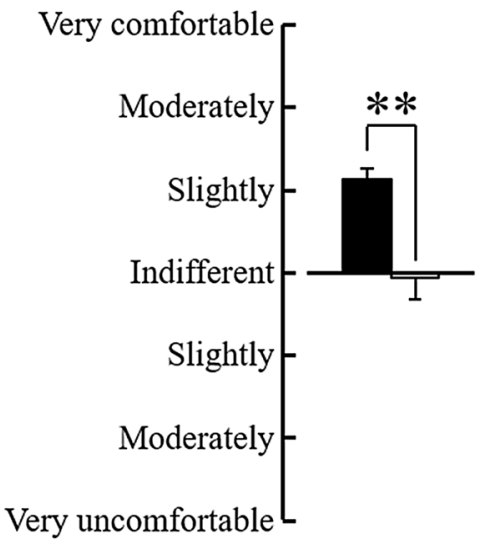

(b) "Relaxed" feeling

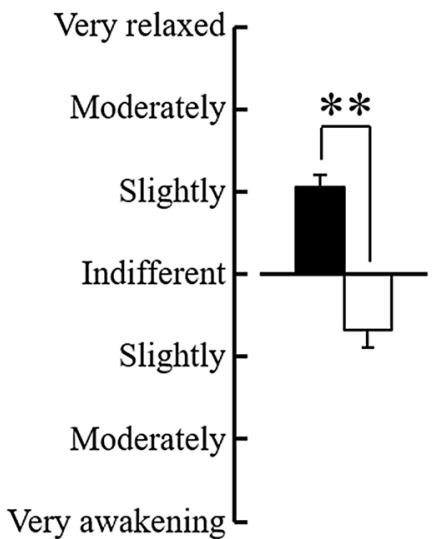

(c) "Natural" feeling

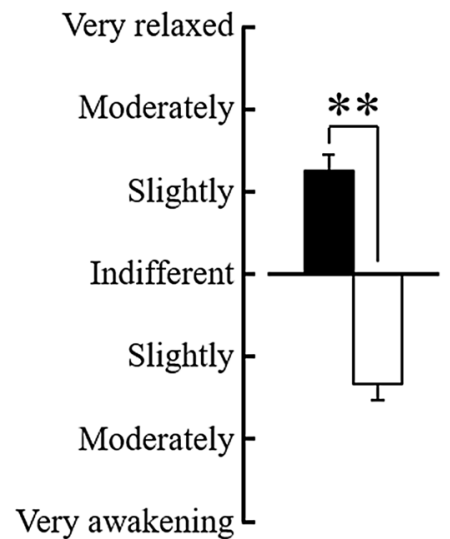

(d) "Warm-cold" feeling

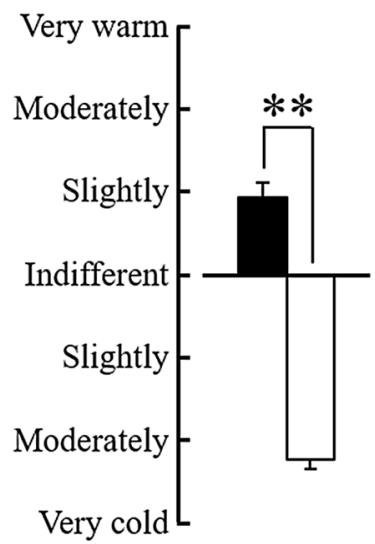

(f) "Dry-moist" feeling

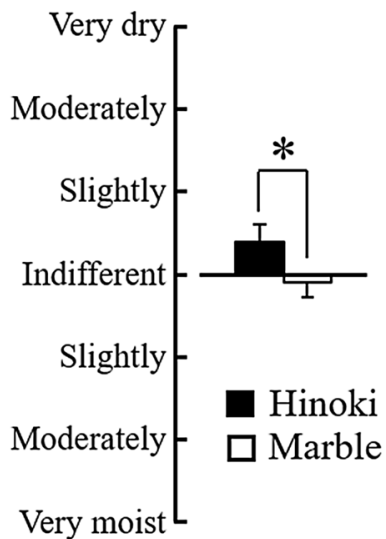

(e) "Uneven-flat" feeling

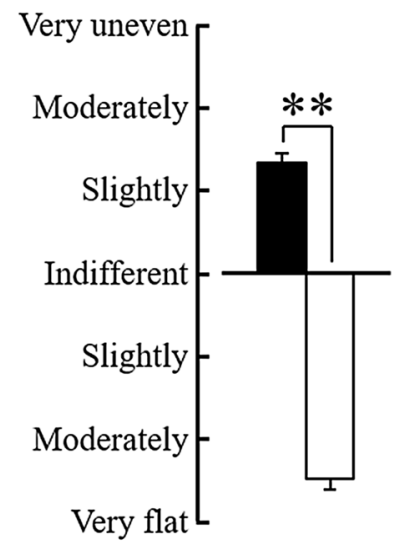

(g) "Soft-hard" feeling

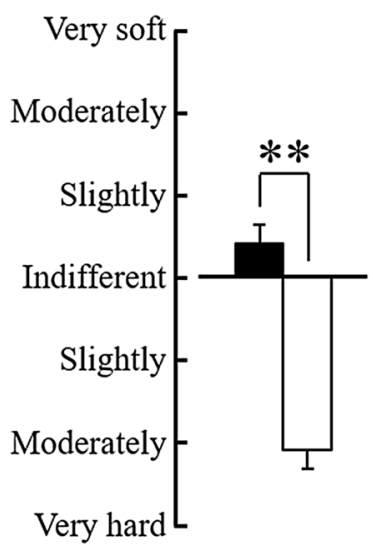

Fig. 6 Subjective feeling measured by the modified semantic differential method after touching hinoki or marble materials. a "Comfortable" feeling, b "relaxed" feeling, c "natural" feeling, d "warm-cold" feeling, e "uneven-flat" feeling, f "dry-moist" feeling, g "soft- hard" feeling. Data are expressed as means \pm standard error, $n=22$, $* * p<0.01, * p<0.05$ as determined by the Wilcoxon signed-rank test; the Holm correction was applied 
uneven", was considered significantly more uneven than marble, which was perceived as "moderately to very flat" (Fig. 6e, $p<0.01$ ). With regard to "dry-moist" feeling, the participants reported feeling "indifferent to slightly dry" after contact with hinoki and "indifferent" after contact with marble, representing a significant difference (Fig. 6f, $p<0.05)$. Finally, with regard to "soft-hard" feeling, hinoki, which was perceived as "indifferent to slightly soft", was considered significantly harder than marble, which was perceived as "moderately hard" (Fig. 6g, $p<0.01$ ).

\section{Discussion}

This study aimed to clarify the effects of touching hinoki wood with the palm of the right hand on left and right prefrontal cortex activity, assessed by TRS, and on autonomic nervous activity, assessed by HRV. The results showed that in comparison with the control (touching marble material), touching hinoki wood significantly decreased the oxy-Hb concentration in the left prefrontal cortex and significantly increased parasympathetic nervous activity according to the 90 -s overall mean values. In addition, in subjective evaluations, we observed differences between hinoki and marble materials in terms of "comfortable", "relaxed", "natural", "warm-cold", "uneven-flat", "dry-moist", and "soft-hard" feelings, and these psychological findings were shown to be consistent with the physiological responses.

Regarding the physiological effects of tactile stimulation of wood with the palm, Ikei et al. [17] examined the effects of tactile stimulation with uncoated white oak wood on brain activity and autonomic nervous activity in comparison with other materials (marble, tile, and stainless steel). The participants touched the surface of each material for $90 \mathrm{~s}$ while sitting with their eyes closed. The results indicated that tactile stimulation with white oak significantly decreased oxy- $\mathrm{Hb}$ concentration in the left and right prefrontal cortices relative to marble, tile, and stainless steel and increased $\ln (\mathrm{HF})-$ reflected parasympathetic nervous activity relative to marble and stainless steel, thereby inducing physiological relaxation [17]. In addition, Ikei et al. [18] reported differences in the effects of tactile stimulation with uncoated white oak and various coated (oil-finished, vitreous-finished, urethane-finished, and mirror-finished) white oak materials. The results indicated that tactile stimulation with uncoated wood for $90 \mathrm{~s}$ calmed prefrontal cortex activity (vs. urethane-finished and mirror-finished wood), increased parasympathetic nervous activity (vs. vitreous-finished, urethane-finished, and mirror-finished wood), and decreased heart rate (vs. mirrorfinished wood), demonstrating a physiological relaxation effect of wood on humans. Further, tactile stimulation with oil- and vitreous-finished wood, which retain the texture of natural (i.e., uncoated) wood, calmed left prefrontal cortex activity and decreased heart rate relative to mirror-finished wood [18]. Our findings on tactile stimulation with hinoki wood are, therefore, consistent with those of previous studies on tactile stimulation by natural wood or near-natural coated wood, demonstrating a physiological relaxation effect of touching wood with the palm of the hand.

Several studies have reported the physiological effects of olfactory stimulation from hinoki, which are consistent with the findings of our research [8-10, 33]. Olfactory stimulation with air-dried hinoki wood calmed prefrontal cortex activity compared with high-temperature-dried wood [8]. Olfactory stimulation with hinoki leaf oil calmed prefrontal cortex activity and increased parasympathetic nervous activity compared with the control condition (air), indicating that olfactory stimulation with hinoki leaf oil can induce physiological relaxation [33]. Inhalation of $\alpha$-pinene [9] and D-limonene [10], which are major odorous components of coniferous trees such as hinoki, increased parasympathetic nervous activity and decreased heart rate compared with control condition (air), indicating physiological relaxation.

To explain this phenomenon, Miyazaki has advocated a "back to nature" theory $[34,35]$. In this theory, he claims that human physiological functions are best adapted to a natural environment, because over $99.99 \%$ of the course of human evolution since our ancestors started evolving from a subset of primates into our current form around 6 to 7 million years ago has been spent in a natural environment. Conversely, we have spent less than $0.01 \%$ of human history in a modern environment, which only started with the beginning of urbanization in the Industrial Revolution. The highly urbanized and artificial environments that we currently inhabit are the root cause of the "stress state" of modern people. We, therefore, enter a relaxed state when exposed to the natural environment or to nature-derived stimulation, which brings us closer to our original natural state as human beings.

In this study, it is thought that tactile stimulation by touching hinoki wood with the palm of the right hand brought about physiological relaxation effects, because wood is a familiar and representative natural material for humans. Previous studies have shown that natural environments or nature-derived stimuli, such as forests [36-42], urban parks [43-45], flowers [46-50], and foliage plants $[51,52]$, induce physiological relaxation in humans. Wood is a familiar natural material which we have many opportunities to touch on a daily basis, and it is used for many household objects, such as interior materials of buildings and houses, furniture (desks and shelves), and stationery. Wood could become one of the effective materials for relieving stress in our modern urban, artificial society. Hinoki, which was used as a wood sample in this study, is one of the representative coniferous trees in Japan and has been used for a long time as a building material for shrines 
and temples, such as the Horyuji Temple, whose pagoda is one of the oldest wooden buildings. Even today, hinoki is used for interiors, such as residential floors and walls.

The novel features of this study are that it dealt with tactile stimulation, for which there are limited physiological data; it used hinoki, which has not been the target of previous studies, as a material; and it conducted simultaneous measurement of prefrontal cortical activity and sympathetic/parasympathetic nervous activity to study the relaxation effects of the material.

In summary, our results show a physiological relaxation effect of tactile contact with hinoki wood, which is one of the representative coniferous trees in Japan. However, the study has certain limitations. First, although we examined the effect of touching wood with the palm of the hand, we did not examine the effect of contact with other body surfaces. Future research should examine the effect of wood on physiological response when it is touched with the sole of the foot, because wood is often used as a flooring material. Second, this study only measured the physiological effects of wood from placing the palm of the hand on the stimulus. It will be necessary to clarify the impact on the physiological response of more active forms of contact, such as stroking the surface of the wood with the hand. Finally, although this study compared noncoated hinoki wood with a nonwood material (marble), it will be necessary to determine the effect of touching hinoki wood with various coatings on the physiological response, because much of the wood used in everyday life is coated.

\section{Conclusions}

Touching hinoki with the palm of the right hand significantly decreased the oxy-Hb concentration in the left prefrontal cortex and increased $\ln (\mathrm{HF})$-reflected parasympathetic nervous activity compared with touching marble. These findings indicate that tactile stimulation of the palm of the hand with hinoki wood calms prefrontal cortex activity and increases parasympathetic nervous activity, thereby inducing physiological relaxation.

Acknowledgements We would like to express our sincere gratitude to MARUHON, Inc. for providing the hinoki and marble materials. We are grateful to Dr. Tatsuya Shibusawa, Dr. Kohta Miyamoto, and Dr. Yukari Matsumura of the Forestry and Forest Products Research Institute for their guidance in the measurement of physical property values.

Funding This work was supported by JSPS KAKENHI Grant no. JP16K18200.

\section{Compliance with ethical standards}

Conflict of interest The authors declare that they have no conflicts of interest.

Ethical approval All procedures performed in studies involving human participants were in accordance with the ethical standards of the institutional and/or national research committee and with the 1964 Helsinki declaration and its later amendments or comparable ethical standards.

Open Access This article is distributed under the terms of the Creative Commons Attribution 4.0 International License (http://creativecommons.org/licenses/by/4.0/), which permits unrestricted use, distribution, and reproduction in any medium, provided you give appropriate credit to the original author(s) and the source, provide a link to the Creative Commons license, and indicate if changes were made.

\section{References}

1. Brod C (1984) Technostress: the human cost of the computer revolution. Addison Wesley, Boston, p 242

2. Salanova M, Llorens S, Cifre E (2013) The dark side of technologies: Technostress among users of information and communication technologies. Int J Psychol 48:422-436

3. United Nations Population Fund (2007) The promise of urban growth. State of World Population 2007: Unleashing the Potential of Urban Growth. United Nations Population Fund, New York, pp 5-13

4. Lederbogen F, Kirsch P, Haddad L, Streit F, Tost H, Schuch P, Wüst S, Pruessner JC, Rietschel M, Deuschle M, Meyer-Lindenberg A (2011) City living and urban upbringing affect neural social stress processing in humans. Nature 474:498-501

5. Song C, Ikei H, Miyazaki Y (2016) Physiological effects of nature therapy: a review of the research in Japan. Int J Environ Res Public Health 13:781

6. Ikei H, Song C, Miyazaki Y (2017) Physiological effects of wood on humans: a review. J Wood Sci 63:1-23

7. Miyazaki Y, Motohashi Y, Kobayashi S (1992) Changes in mood by inhalation of essential oils in humans II. Effect of essential oils on blood pressure, heart rate, R-R intervals, performance, sensory evaluation and POMS (in Japanese). Mokuzai Gakkaishi 38:909-913

8. Ikei H, Song C, Lee J, Miyazaki Y (2015) Comparison of the effects of olfactory stimulation by air-dried and high-temperaturedried wood chips of hinoki cypress (Chamaecyparis obtusa) on prefrontal cortex activity. J Wood Sci 61:537-540

9. Ikei H, Song C, Miyazaki Y (2016) Effects of olfactory stimulation by $\alpha$-pinene on autonomic nervous activity. J Wood Sci 62:568-572

10. Joung D, Song C, Ikei H, Okuda T, Igarashi M, Koizumi H, Park BJ, Yamaguchi T, Takagaki M, Miyazaki Y (2014) Physiological and psychological effects of olfactory stimulation with D-limonene. Adv Hortic Sci 28:90-94

11. Tsunetsugu Y, Miyazaki Y, Sato H (2002) The visual effects of wooden interiors in actual-size living rooms on the autonomic nervous activities. J Physiol Anthropol Appl Hum Sci 21:297-300

12. Tsunetsugu Y, Miyazaki Y, Sato H (2005) Visual effects of interior design in actual-size living rooms on physiological responses. Build Environ 40:1341-1346 
13. Tsunetsugu Y, Miyazaki Y, Sato H (2007) Physiological effects in humans induced by the visual stimulation of room interiors with different wood quantities. J Wood Sci 53:11-16

14. Sakuragawa S, Miyazaki Y, Kaneko T, Makita T (2005) Influence of wood wall panels on physiological and psychological responses. J Wood Sci 51:136-140

15. Morikawa T, Miyazaki Y, Kobayashi S (1998) Time-series variations of blood pressure due to contact with wood. J Wood Sci 44:495-497

16. Sakuragawa S, Kaneko T, Miyazaki Y (2008) Effects of contact with wood on blood pressure and subjective evaluation. J Wood Sci 54:107-113

17. Ikei H, Song C, Miyazaki Y (2017) Physiological effects of touching wood. Int J Environ Res Public Health 14:801

18. Ikei H, Song C, Miyazaki Y (2017) Physiological effects of touching coated wood. Int J Environ Res Public Health 14:773

19. ASTM C518-10 (2003) Standard test method for steady-state thermal transmission properties by means of the heat flow meter apparatus. ASTM, West Conshohocken

20. ISO 8301 (1991) Thermal insulation determination of steadystate thermal resistance and related properties heat flow meter apparatus. ISO, Geneva

21. Ohmae E, Ouchi Y, Oda M, Suzuki T, Nobesawa S, Kanno T, Yoshikawa E, Futatsubashi M, Ueda Y, Okada H, Yamashita Y (2006) Cerebral hemodynamics evaluation by near-infrared time-resolved spectroscopy: correlation with simultaneous positron emission tomography measurements. Neuroimage 29:697-705

22. Ohmae E, Oda M, Suzuki T, Yamashita Y, Kakihana Y, Matsunaga A, Kanmura Y, Tamura M (2007) Clinical evaluation of time-resolved spectroscopy by measuring cerebral hemodynamics during cardiopulmonary bypass surgery. J Biomed Opt 12:9

23. Torricelli A, Contini D, Pifferi A, Caffini M, Re R, Zucchelli L, Spinelli L (2014) Time domain functional nirs imaging for human brain mapping. Neuroimage 85:28-50

24. Camm AJ, Malik M, Bigger JT, Breithardt G, Cerutti S, Cohen RJ, Coumel P, Fallen EL, Kennedy HL, Kleiger RE, Lombardi F (1996) Heart rate variability standards of measurement, physiological interpretation, and clinical use. Circulation 93:1043-1065

25. Kobayashi H, Ishibashi K, Noguchi H (1999) Heart rate variability; an index for monitoring and analyzing human autonomic activities. Appl Hum Sci 18:53-59

26. Kanaya N, Hirata N, Kurosawa S, Nakayama M, Namiki A (2003) Differential effects of propofol and sevoflurane on heart rate variability. Anesthesiology 98:34-40

27. Sawada Y, Ohtomo N, Tanaka Y, Tanaka G, Yamakoshi K, Terachi S, Shimamoto K, Nakagawa M, Satoh S, Kuroda S, Iimura O (1997) New technique for time series analysis combining the maximum entropy method and non-linear least squares method: its value in heart rate variability analysis. Med Biol Eng Comput $35: 318-322$

28. Task Force of the European Society of Cardiology and the North American Society of Pacing and Electrophysiology (1996) Heart rate variability: standards of measurement, physiological interpretation and clinical use. Circulation 93:1043-1065

29. Pagani M, Lombardi F, Guzzetti S, Rimoldi O, Furlan RA, Pizzinelli P, Sandrone G, Malfatto G, Dell'Orto S, Piccaluga E (1986) Power spectral analysis of heart rate and arterial pressure variabilities as a marker of sympath o-vagal interaction in man and conscious dog. Circ Res 59:178-193

30. Kobayashi H, Park BJ, Miyazaki Y (2012) Normative references of heart rate variability and salivary alpha-amylase in a healthy young male population. J Physiol Anthropol 31:9
31. Osgood CE, Suci GJ, Tannenbaum P (1957) The measurement of meaning. University of Illinois Press, Urbana

32. Victor A, Elsässer A, Hommel G, Blettner M (2010) Judging a plethora of $p$-values: how to contend with the problem of multiple testing. Part 10 of a series on evaluation of scientific publications. Dtsch Arztebl Int 107:50-56

33. Ikei H, Song C, Miyazaki Y (2015) Physiological effect of olfactory stimulation by hinoki cypress (Chamaecyparis obtusa) leaf oil. J Physiol Anthropol 34:44

34. Miyazaki Y, Park BJ, Lee J (2011) Nature therapy. In: Osaki MBA, Nakagami K (eds) Designing our future: perspectives on bioproduction, ecosystems and humanity. United Nations University Press, Tokyo, pp 407-412

35. O' Grady MA, Meinecke L (2015) Silence: because what's missing is too absent to ignore. J Societ Cult Res 1:1-25

36. Park BJ, Tsunetsugu Y, Kasetani T, Hirano H, Kagawa T, Sato M, Miyazaki Y (2007) Physiological effects of Shinrin-yoku (taking in the atmosphere of the forest)—using salivary cortisol and cerebral activity as indicators. J Physiol Anthropol 26:123-128

37. Lee J, Park BJ, Tsunetsugu Y, Kagawa T, Miyazaki Y (2009) The restorative effects of viewing real forest landscapes: based on a comparison with urban landscapes. Scand J For Res 24:227-234

38. Park BJ, Tsunetsugu Y, Kasetani T, Kagawa T, Miyazaki Y (2010) The physiological effects of Shinrin-yoku (taking in the forest atmosphere or forest bathing): evidence from field experiments in 24 forests across Japan. Environ Health Prev Med 15:18-26

39. Tsunetsugu Y, Park BJ, Miyazaki Y (2010) Trends in research related to "shinrin-yoku" (taking in the forest atmosphere or forest bathing) in Japan. Environ Health Prev Med 15:27-37

40. Lee J, Park BJ, Tsunetsugu Y, Ohira T, Kagawa T, Miyazaki Y (2011) Effect of forest bathing on physiological and psychological responses in young Japanese male subjects. Public Health 125:93-100

41. Tsunetsugu Y, Lee J, Park BJ, Tyrvainen L, Kagawa T, Miyazaki Y (2013) Physiological and psychological effects of viewing urban forest landscapes assessed by multiple measurements. Landsc Urban Plan 113:90-93

42. Lee J, Tsunetsugu Y, Takayama N, Park BJ, Li Q, Song C, Komatsu M, Ikei H, Tyrväinen L, Kagawa T, Miyazaki Y (2014) Influence of forest therapy on cardiovascular relaxation in young adults. Evid Based Complement Altern Med 2014:834360

43. Song C, Ikei H, Igarashi M, Miwa M, Takagaki M, Miyazaki Y (2014) Physiological and psychological responses of young males during spring-time walks in urban parks. J Physiol Anthropol 33:8

44. Song C, Ikei H, Igarashi M, Takagaki M, Miyazaki Y (2015) Physiological and psychological effects of a walk in urban parks in fall. Int J Environ Res Public Health 12:14216-14228

45. Song C, Joung D, Ikei H, Igarashi M, Aga M, Park BJ, Miwa M, Takagaki M, Miyazaki Y (2013) Physiological and psychological effects of walking on young males in urban parks in winter. J Physiol Anthropol 32:18

46. Ikei H, Komatsu M, Song C, Himoro E, Miyazaki Y (2014) The physiological and psychological relaxing effects of viewing rose flowers in office workers. J Physiol Anthropol 33:6

47. Igarashi M, Aga M, Ikei H, Namekawa T, Miyazaki T (2015) Physiological and psychological effects on high school students of viewing real and artificial pansies. Int J Environ Res Public Health 12:2521-2531

48. Igarashi M, Yamamoto T, Lee J, Song C, Ikei H, Miyazaki Y (2014) Effects of stimulation by three-dimensional natural images on prefrontal cortex and autonomic nerve activity: a 
comparison with stimulation using two-dimensional images. Cogn Process 15:551-556

49. Igarashi M, Ikei H, Song C, Miyazaki Y (2014) Effects of olfactory stimulation with rose and orange oil on prefrontal cortex activity. Complement Ther Med 22:1027-1031

50. Igarashi M, Song C, Ikei H, Ohira T, Miyazaki Y (2014) Effect of olfactory stimulation by fresh rose flowers on autonomic nervous activity. J Altern Complement Med 20:727-731
51. Ikei H, Song C, Igarashi M, Namekawa T, Miyazaki Y (2014) Physiological and psychological relaxing effects of visual stimulation with foliage plants in high school students. Adv Hortic Sci 28:111-116

52. Park SA, Song C, Choi JY, Son KC, Miyazaki Y (2016) Foliage plants cause physiological and psychological relaxation-as evidenced by measurements of prefrontal cortex activity and profile of mood states. HortScience 51:1308-1312 